\title{
Performance of Segmental Post-Tensioned Concrete Beams Exposed to High Fire Temperature
}

\author{
H. M. Hekmet \\ Department of Civil Engineering \\ Al-Farabi University College \\ Baghdad, Iraq \\ maithem_haider@yahoo.com
}

\author{
A. F. Izzet \\ Department of Civil Engineering \\ University of Baghdad \\ Baghdad, Iraq \\ amer.f@coeng.uobaghdad.edu.iq
}

\begin{abstract}
The present study illustrates observations, record accurate description and discussion about the behavior of twelve tested, simply supported, precast, prestressed, segmental, concrete beams with different segment numbers exposed to high fire temperatures of $300^{\circ} \mathrm{C}, 500^{\circ} \mathrm{C}$, and $700^{\circ} \mathrm{C}$. The test program included thermal tests by using a furnace manufactured for this purpose to expose to high burning temperature (fire flame) nine beams which were loaded with sustaining dead load throughout the burning process. The beams were divided into three groups depending on the precast segments number. All had an identical total length of $3150 \mathrm{~mm}$ but each had different segment number $(9,7$, and 5 segments), in other words, different segment lengths. To simulate genuine fire disasters, the nine beams were exposed to high-temperature flames for one hour along with the control specimens. The selected temperatures were $300^{\circ} \mathrm{C}\left(572^{\circ} \mathrm{F}\right), 500^{\circ} \mathrm{C}$ $\left(932^{\circ} \mathrm{F}\right)$, and $700^{\circ} \mathrm{C}\left(1292^{\circ} \mathrm{F}\right)$ as recommended by the standard fire curve (ASTM-E119). The specimens were cooled gradually at ambient laboratory conditions. The performance of the prestressed segmental concrete beams through the burning process was described with regard to the beams camber, spalling, and occurred deterioration.
\end{abstract}

Keywords-burning temperature, fire flame; gradual cooling; segmental beam

\section{INTRODUCTION}

Segmental box girder bridges represent one major recent development in bridge engineering. This method of construction has many advantages like substantial economical savings due to the possibility of weather-independent segment production, shorter construction periods, simple element assembly at job site, replace ability of tendons, the concreting and prestressing operations are independent, small light segments, the profiling of the main external steel is easier to check, and the friction may be reduced [1]. The strength of reinforced concrete (RC) and prestressed concrete decreases after fire exposure. The basic fire safety objectives are to protect life and prevent failure. Following a fire, even if no collapse occurs, there is always a possibility of fire-induced damage. This research seeks to give an explanation and a simplified estimation of fire-induced damages produced in precast segmental prestressed concrete (SPC) beams via monitoring experimentally the behavior of internally prestressed precast concrete segmental beams with selective parameters such as segment length, number of joints between segments, and the exposure to different burning temperatures. Authors in [2, 3] presented the results of nonlinear finite element analysis on segmental concrete beams with external tendons. Authors in [4] investigated the structural behavior of dry joined externally prestressed segmental (EPS) beams under combined stresses, i.e. bending, shear and torsion stresses. It was found that the presence of torsion in beams reduces the vertical load and vertical deflection at the onset of nonlinearity, failure load and further, it would alter the failure mechanism. A reduction in the load-carrying capacity of EPS beams can be compensated by higher pre-stressing and by increasing stirrup reinforcement in the joint regions and to ensure serviceability. The joints in the supported regions should still be sufficiently pre-stressed under service load conditions.

Previous works dealt with high temperature residual mechanical properties of concrete, mild steel and prestressing steel and how high temperature residual properties affect the ultimate strength of the element. Authors in [5] studied the mechanical properties of high-performance concrete (HPC) and the normal-strength concrete (NSC) after exposure to high temperature. The residual compressive strength was examined after the concrete specimens were subjected to a temperature of $800^{\circ} \mathrm{C}$. Authors in [6] compared the strength and durability performance of normal and high-strength pozzolanic concretes including silica fume, fly ash, and blast furnace slag at high temperatures up to $800^{\circ} \mathrm{C}$. Authors in [7] reported that concrete can suffer large damage when exposed to fire, although it has low heat conductivity. Author in [8] stated that concrete materials have significant variations, therefore the structural fire safety capacity of concrete is very complex. Prestressed normal strength concrete (NSC) and high-strength concrete (HSC) exposed to fire require constitutive relationships to offer active modeling and to meet particular fire performance standards for fire-resistant prestressed concrete behavior. In this research, formulations were proposed to estimate the parameters that affect the behavior of unconfined prestressed concrete at high temperatures. Authors in [9] studied the mechanical properties of prestressing wires through and after the exposure to fire. The results were compared with the existing ones from the relevant literature and design codes, and empirical formulas were suggested. Researchers concluded that although the prior examinations provided beneficial results for 
the mechanical characteristics of prestressing steel at high temperatures, the information found was somewhat scattered and still inadequate.

\section{SPC BEAMS SET UP}

The experimental program consisted of twelve simply supported segmental prestressed concrete beams divided into three groups depending on the precast segments number. All the SPC beams were selected and designed with 3150,400 and $400 \mathrm{~mm}$ length, depth and width, respectively. The first group consisted of SPC beams with 9 segments $(350 \mathrm{~mm}$ segment length), the second group with 7 segments $(450 \mathrm{~mm}$ segment length), while the last group had 5 segments $(630 \mathrm{~mm}$ segment length). Figure 1 shows the schematic shape of the SPC beams for each group. Figure 2 demonstrates the details of the two opposite contact surfaces of reinforced concrete precast segments, which have been used to assemble the SPC beams, the first consisted projections as shear connecters (keys), in contrast the other consisted pits to engage with the projections.

(a)

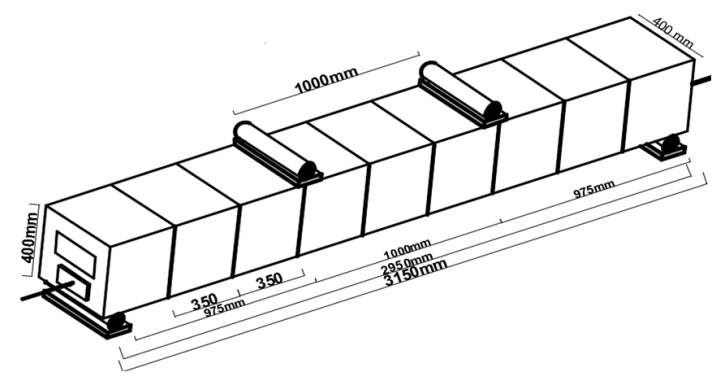

(b)

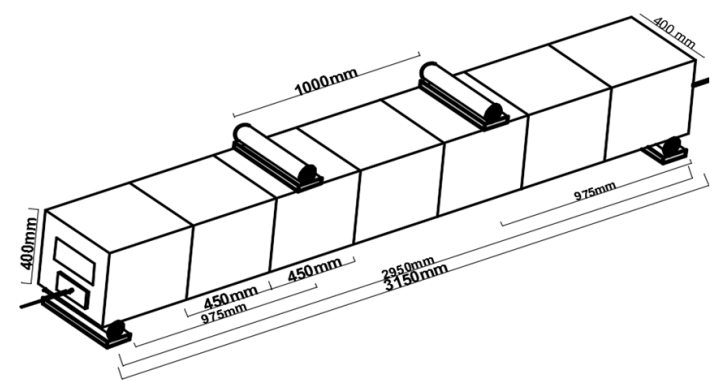

(c)

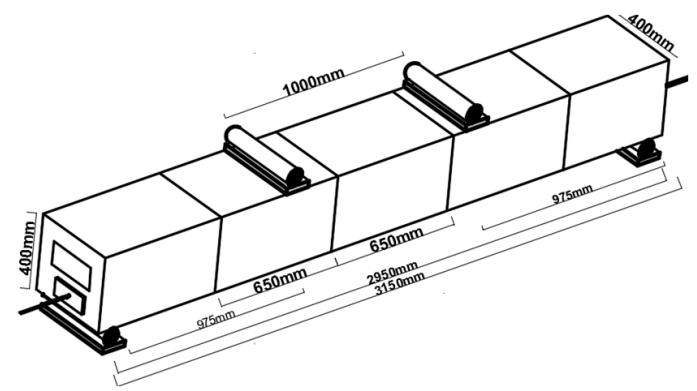

Fig. 1. Schematic shape and dimensions of the tested SPC beams: (a) Group I, (b) Group II, (c) Group IIII

The reinforcement details for the three groups are illustrated in Figure 3. The deformed $8 \mathrm{~mm}$ diameter bar of 486 and $640 \mathrm{MPa}$, its yield stress and ultimate strength, were respectively used for the longitudinal and ties reinforcement.

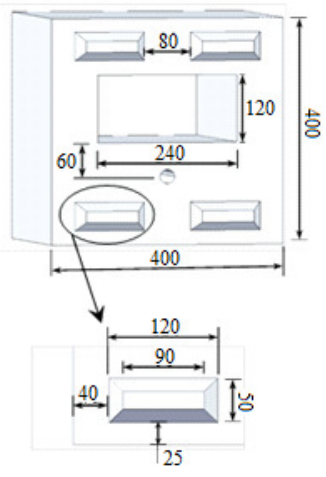

(a). front view surface

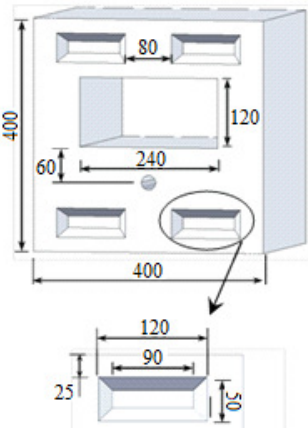

(b). behind view surface
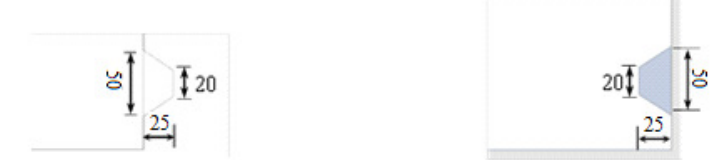

Side view of the shear keys
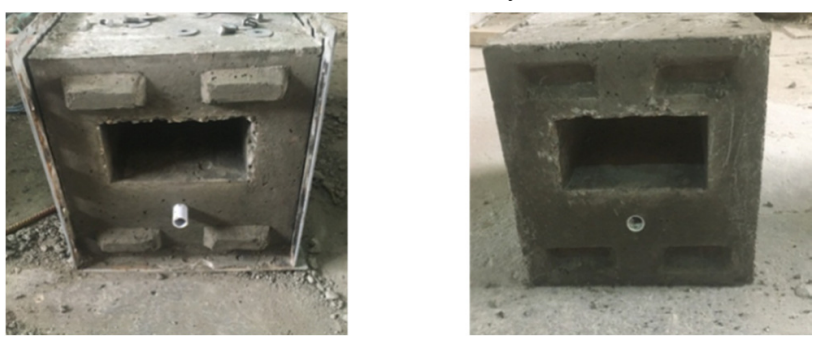

Precast reinforced concrete segments

Fig. 2. Configuration of SPC beam segments (all dimensions in $\mathrm{mm}$ )

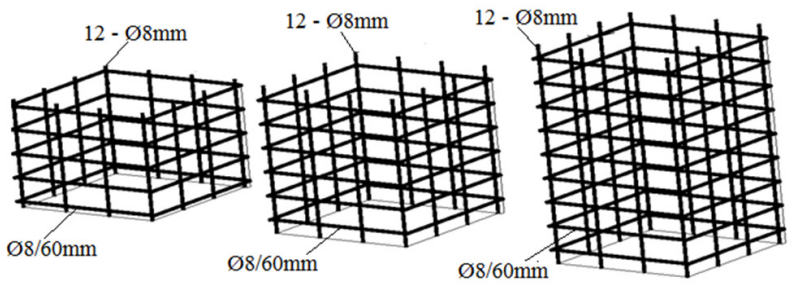

Fig. 3. Reinforcement details of segments for each group of the tested SPC beams

The tested SPC beams passed through two stages of manufacturing. First, the segments of each beam had been cast (using the short line method) and cured, after reaching the specified concrete strength of $40 \mathrm{MPa}$, the segments were assembled together in groups. After that, eccentric prestressing force of $120 \mathrm{kN}$ was applied from one end after insertion of low relaxation 7 -wires strand $(12.7 \mathrm{~mm}$ diameter), grade 270 , in the plastic tube which had been fixed before casting. The adopted prestressing force was selected so that it satisfied the limits of the ACI $318 \mathrm{M}-14$ Code. Table I lists the suggested variables. Two stages of experimental tests were carried out on the SPC beams.

\section{EXPOSURE TO FIRE TEST}

Three SPC beams of each group (with its control specimens) were exposed to high temperatures of 300,500 , and 
$700^{\circ} \mathrm{C}$ while applying uniformly a constant dead load of $3.22 \mathrm{kN} / \mathrm{m}$ by using nineteen concrete blocks, $50 \mathrm{~kg}$ each for similar exposure period of $1 \mathrm{~h}$ after reaching the target temperature. After that, all beams were allowed to cool at ambient laboratory temperature. The burning stage comprised of positioning the SPC beams above their idealized simply supported ends, and the deflection due to the constant dead load and the camber change due to fire were measured using a dial gauge of $0.002 \mathrm{~mm} /$ div sensitivity. The temperature was monitored by a digital thermometer reader with three thermocouple sensor wires type K (Nickel-Chromium/NickelAlumel), which can be used at temperatures up to $1100^{\circ} \mathrm{C}$. The sensors were set at three points with equal distances in the top region between the furnace cover and the SPC beam at the mid, right and left of the top case of the furnace. The fire flame test procedure is illustrated in Figures 4 and 5.

TABLE I. SEGMENTAL PRESTRESSED CONCRETE BEAMS

\begin{tabular}{|c|c|c|c|c|}
\hline Group & Specimen & $\begin{array}{c}\text { Segment } \\
\text { number }\end{array}$ & $\begin{array}{c}\text { Segment } \\
\text { length (mm) }\end{array}$ & $\begin{array}{c}\text { Burning } \\
\left.\text { temperature ( }{ }^{\circ} \mathbf{C}\right)\end{array}$ \\
\hline \multirow{4}{*}{ Group I } & SPC-9-R & 9 Segments & 350 & unburned \\
\cline { 2 - 5 } & SPC-9-300 & 9 Segments & 350 & 300 \\
\cline { 2 - 5 } & SPC-9-500 & 9 Segments & 350 & 500 \\
\cline { 2 - 5 } & SPC-9-700 & 9 Segments & 350 & 700 \\
\hline \multirow{4}{*}{ Group II } & SPC-7-R & 7 Segments & 450 & unburned \\
\cline { 2 - 5 } & SPC-7-300 & 7 Segments & 450 & 300 \\
\cline { 2 - 5 } & SPC-7-500 & 7 Segments & 450 & 500 \\
\cline { 2 - 5 } & SPC-7-700 & 7 Segments & 450 & 700 \\
\hline \multirow{5}{*}{ Group III } & SPC-5-R & 5 Segments & 630 & unburned \\
\cline { 2 - 5 } & SPC-5-300 & 5 Segments & 630 & 300 \\
\cline { 2 - 5 } & SPC-5-500 & 5 Segments & 630 & 500 \\
\cline { 2 - 5 } & SPC-5-700 & 5 Segments & 630 & 700 \\
\hline
\end{tabular}

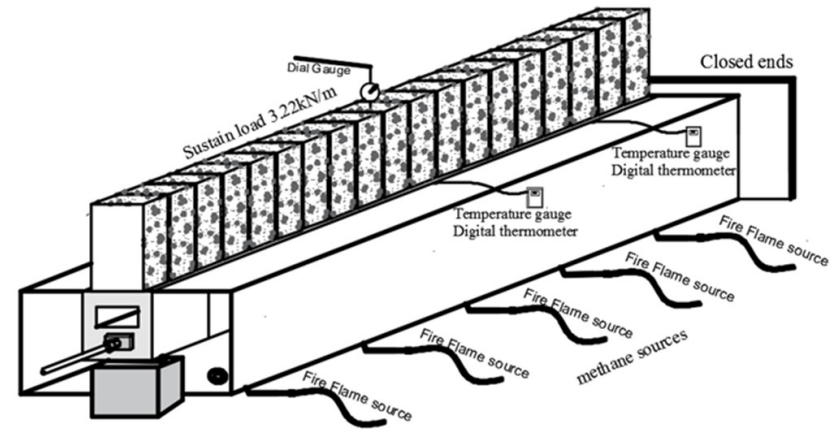

Fig. 4. Furnace schematic shape and burning process

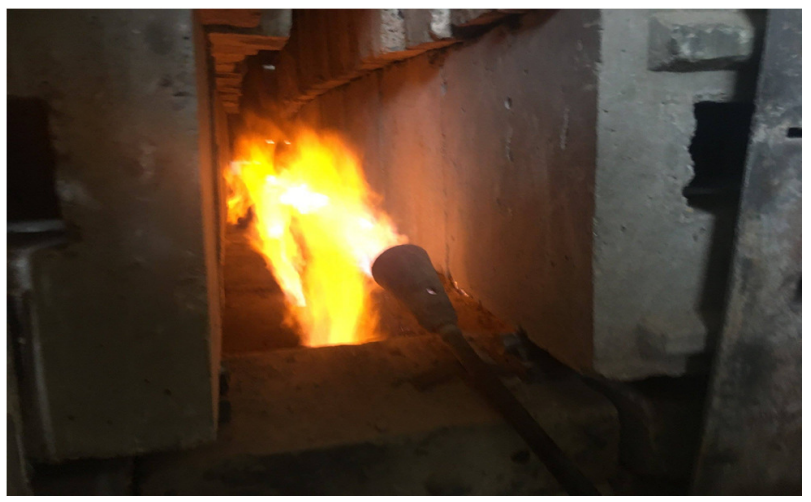

Fig. 5. Burning process

\section{RESULTS AND DISCUSSION}

\section{A. Camber at Prestressing Stage}

The effect of the prestressing force, combined with the beam self-weight, causes a net upward deflection at the midspan of the prestressed beam before superimposed dead and live loads are applied. The SPC beams camber was measured with a mechanical dial gauge of $0.002 \mathrm{~mm} / \mathrm{div}$ set in the midspan of the beam while the prestressing process was performed. The results, exhibited in Table II, show a significant camber decrease with decreasing number of segments. It reveals a decrease percentage in the average camber by $79 \%$ for SPC beams of 7 segments (Group II) and 62\% for SPC beams of 5 segments (Group III) compared with the SPC beams of 9 segments (Group I). The regular cracks performed in the segmental beams are comprehended by the dry joints that affect the behavior of camber, due to the high stiffness of beams with the small number of joints in the SPC beams with less number of segments.

\section{B. Deflection Due to Superimposed Load}

Nineteen concrete blocks for each specimen were placed over the length of the SPC beams during the period of exposure to burning temperature. The measured deflections, listed in Table II, were set under the beam while these blocks were set above the SPC beams. The results show a conflicting relation between the deflection and the number of segments composing the SPC beam, in other words between the SPC beam stiffness and the number of segments.

TABLE II. INITIAL PRESTRESSING CAMBER AFTER APPLYING SUSTAIN LOAD ON SPC BEAMS

\begin{tabular}{|c|c|c|c|c|c|c|}
\hline & Group No. & 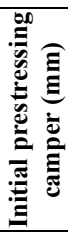 & 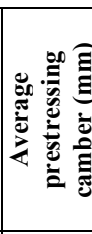 & 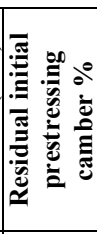 & 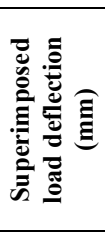 & 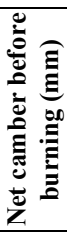 \\
\hline & SPC-9-R & 2.9 & & & - & - \\
\hline ? & SPC $-9-300 \mathrm{C}^{\circ}$ & 2.8 & & & 0.36 & 2.44 \\
\hline 苛 & SPC-9-500C ${ }^{\circ}$ & 3.1 & & 100 & 0.36 & 2.74 \\
\hline & SPC-9-700C & 3 & & & 0.36 & 2.64 \\
\hline & SPC-7-R & 2.3 & & & - & - \\
\hline $\begin{array}{l}\exists \\
\cong\end{array}$ & $\mathrm{SPC}-7-300 \mathrm{C}^{\circ}$ & 2.2 & 23 & & 0.27 & 1.93 \\
\hline ல் & SPC-7-500C ${ }^{\circ}$ & 2.4 & 2.5 & ( & 0.27 & 2.13 \\
\hline & SPC $-7-700 \mathrm{C}^{\circ}$ & 2.2 & & & 0.27 & 1.93 \\
\hline$\Xi$ & SPC-5-R & 1.8 & & & - & - \\
\hline 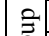 & $\mathrm{SPC}^{-5}-300 \mathrm{C}^{\circ}$ & 1.6 & 1.8 & 62 & 0.2 & 1.4 \\
\hline 我 & SPC $-5-500 \mathrm{C}^{\circ}$ & 1.8 & & & 0.2 & 1.6 \\
\hline 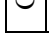 & SPC-5-700C ${ }^{\circ}$ & 1.9 & & & 0.2 & 1.7 \\
\hline
\end{tabular}

\section{Thermal Test Results}

The burning process comprised of setting fire until reaching the target temperature, then, after an exposure period of $1 \mathrm{~h}$ to the target temperature the fire was turned off and a gradual cooling was performed by removing the furnace cover case and 
lefting the SPC beams with their control specimens in the ambient air (lab conditions).

\section{1) Compressive Strength of Concrete $\left(f^{\prime} c\right)$}

Authors in [6] reported that there are three testing methods available to find the residual compressive strength of the concrete at high temperatures: stressed test, unstressed test, and unstressed residual strength test. The first two methods opt to find concrete strength during high temperatures, while the last is excellent for determining the residual properties after exposure to high temperature. It was observed that the third method gives less strength and is therefore more appropriate for obtaining limiting values. This method has been adopted to find the residual concrete strength. The test results of compressive strength, as shown in Table IIII for the $150 \mathrm{~mm}$ specimens showed reducing in the compressive strength results with increasing burning temperature.

TABLE III. FIRE EFFECTS ON COMPRESSIVE STRENGTH*

\begin{tabular}{|c|c|c|c|c|c|c|}
\hline & $\begin{array}{c}f_{\text {cu }} \\
(\mathbf{M P a})\end{array}$ & $\begin{array}{c}f^{\prime} \mathbf{c}^{*} \\
(\mathbf{M P a})\end{array}$ & $\begin{array}{c}\text { Average } \\
\text { residual } \\
\text { strength \% }\end{array}$ & $\begin{array}{c}f^{\prime} \mathrm{c}^{* *} \\
\text { (MPa) }\end{array}$ & $\begin{array}{c}\text { Residual } \\
\text { strength } \\
{[8]}\end{array}$ \\
\hline \multirow{4}{*}{ 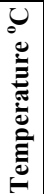 } & ambient & 42 & 33.6 & 100 & 33.6 & 100 \\
\hline & 300 & 39 & 31.2 & 93 & 32.1 & 95.5 \\
\hline & 500 & 28 & 22.4 & 67 & 24.4 & 72.6 \\
\hline & 700 & 16 & 12.8 & 38 & 13.9 & 41.4 \\
\hline
\end{tabular}

** Post fire concrete strength proposed equation by [8]

The loss of strength was characteristically varying depending from the burning temperature. $\mathrm{Up}$ to $300^{\circ} \mathrm{C}$, only a small portion of the original strength was lost, about $7 \%$. Severe loss in the strength mostly happened within the range of $500-700^{\circ} \mathrm{C}$ burning temperature and was $33 \%-62 \%$, respectively. The proposed equations [8] are compared in Table III with the test results. It is clear that there is a good agreement between the experimental results and the values given by the proposed equations. The compressive strength (Figure 6) exhibits a rapid decrease above $300^{\circ} \mathrm{C}$, due to the dehydration of calcium hydroxide in the cement which begins when the temperature reaches about $400^{\circ} \mathrm{C}$, generating more water vapor and also causing an additional significant reduction in the physical strength of the material [10]. The residual strength exhibits a rapid decrease above $300^{\circ} \mathrm{C}$ as shown in Figure 7.

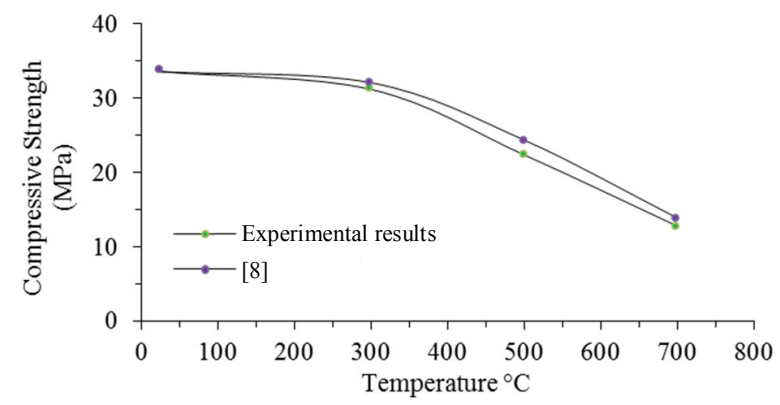

Fig. 6. Burning temperature versus compressive strength

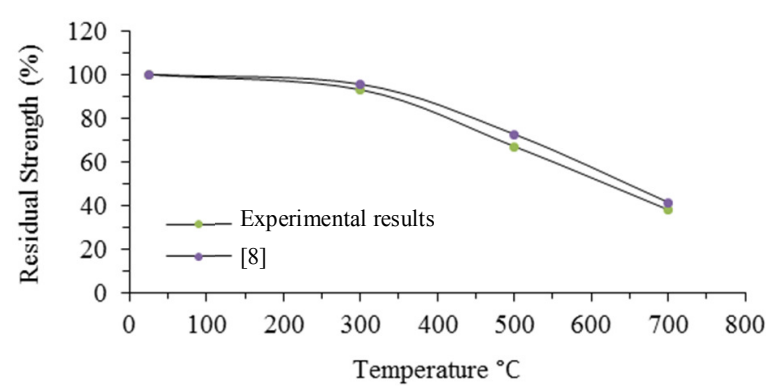

Fig. 7. Burning temperature versus residual strength

\section{2) Properties of Steel Reinforcement Bars}

Concrete structural properties after exposure to high temperature cannot be reversed to the original values. In contrast, steel structures usually return approximately to their original condition after cooling. This is caused by irreversible transformations in the chemical and physical properties of the cement itself [10]. Authors in [11] reported that when a temperature increment occurs, a significant drop in the value of steel yield strength and steel modulus of elasticity emerges. However, when the structure is cooled down, reinforcing steel properties usually recover the most of their original condition. So, real deterioration happens when the reinforcement in some structural elements becomes useless due to the failure of bar anchorage after exposure to fire. Authors in [12] reported two distinguished types of tensile tests of steel at high temperatures to find material properties: transient-state and steady-state tests. In the transient-state tests, the test specimen is under constant load and under constant temperature rise. The heating rate in the transient state tests is $20^{\circ} \mathrm{C} / \mathrm{min}$. Temperature and strain are measured during the test. While in the steady-state tests, the test specimen are burned up to a definite temperature. A tensile test follows. The steady state tests can be carried out either as strain or as load controlled. The steady-state test is more adequate than the transient-state test and therefore that method is more frequently used. The second test method was conducted in this research: three reinforcing steel specimens were burned at different burning temperatures. After cooling stage, tensile tests were carried out. Table IV lists the burning effect on the properties of steel reinforcement bars. Mechanical properties of the steel reinforcement bars after burning at temperature of $300^{\circ} \mathrm{C}$ were not affected, but a significant drop in the value of steel reinforcement properties was observed at burning temperatures of 500 and $700^{\circ} \mathrm{C}$.

TABLE IV. FIRE EFFECTS ON THE PROPERTIES OF STEEL BARS

\begin{tabular}{|c|c|c|c|c|c|}
\hline & $\begin{array}{l}\text { Yield tensile } \\
\text { stress (MPa) }\end{array}$ & $\begin{array}{c}\text { Residual } \\
\text { yield tensile } \\
\text { stress \% } \\
\end{array}$ & $\begin{array}{c}\text { Ultimate } \\
\text { tensile stress } \\
(\mathrm{MPa}) \\
\end{array}$ & $\begin{array}{c}\text { Residual } \\
\text { ultimate tensile } \\
\text { stress \% } \\
\end{array}$ \\
\hline \multirow{4}{*}{ 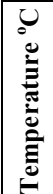 } & ambient & 486 & 100 & 640 & 100 \\
\hline & 300 & 484 & 100 & 630 & 98 \\
\hline & 500 & 462 & 95 & 602 & 94 \\
\hline & 700 & 379 & 78 & 461 & 72 \\
\hline
\end{tabular}

The percentages of residual yield tensile stress and ultimate tensile strength were 95.78 and $94.72 \%$ at $500^{\circ} \mathrm{C}$ and $700^{\circ} \mathrm{C}$ 
respectively. The results are in good agreement to the ones obtained in [13-15].

\section{3) Strand}

The behavior of the prestressing strand is not like that of mild steel, where by cooling, the material will restore less amount of its original state. The effect of burning on the properties of strand is summarized in Table V. The results reveal that, the mechanical properties of the strand were not affected at burning temperature of $300^{\circ} \mathrm{C}$, but at $500^{\circ} \mathrm{C}$ and $700^{\circ} \mathrm{C}$ effects were observed, as was also by other studies. Authors in [16] reported the same observation and added that, prestressing steel losses almost or all of its non-linear behavior at temperatures above $500^{\circ} \mathrm{C}$. Authors in [9] reported that the prestressing steel properties were more sensitive than reinforcing steel bar properties at identical fire temperatures. Equations for calculating yield and ultimate residual stress of prestressing strand where proposed. The loss percentages of $79.42 \%$ and $76.43 \%$ of the residual yield stress and residual ultimate tensile strength at temperature $500^{\circ} \mathrm{C}$ and $700^{\circ} \mathrm{C}$ were observed respectively. They are in good agreement with the findings in [9].

TABLE V. FIRE EFFECT ON THE PROPERTIES OF PRESTRESSING STRAND

\begin{tabular}{|c|c|c|c|c|c|c|c|}
\hline & \multirow{2}{*}{ 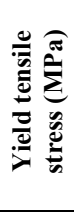 } & \multirow{2}{*}{ 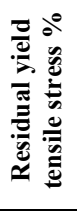 } & \multirow{2}{*}{ 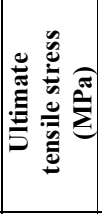 } & \multirow{2}{*}{ 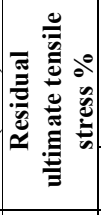 } & \multicolumn{2}{|r|}{ [9] } \\
\hline & & & & & & \begin{tabular}{|c|c}
$\begin{array}{c}\text { Residual } \\
\text { yield } \%\end{array}$ \\
\end{tabular} & $\begin{array}{c}\text { Residual } \\
\text { ultimate \% }\end{array}$ \\
\hline \multirow{4}{*}{ 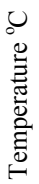 } & ambient & 1720 & 100 & 1860 & 100 & 100 & 100 \\
\hline & 300 & 1700 & 99 & 1850 & 99 & 100 & 100 \\
\hline & 500 & 1359 & 79 & 1414 & 76 & 82.7 & 80 \\
\hline & 700 & 722 & 42 & 800 & 43 & 47.5 & 44 \\
\hline
\end{tabular}

\section{4) Camber at Burning and Cooling Stage}

SPC beams of different segment lengths but identical in total length were subjected to fire test (Table I). Sustain load $(3.22 \mathrm{kN} / \mathrm{m})$ was applied on the SPC beams simultaneously with the exposure to high temperature. The furnace temperature was applied as recommended by ASTM-E119. The beams passed through three stages within burning and cooling cycle. At the first stage, they reached the target temperature of $300^{\circ} \mathrm{C}$, $500^{\circ} \mathrm{C}$ or $700^{\circ} \mathrm{C}$. This took approximately 5,7 and $12 \mathrm{~min}$ respectively. Then, the temperature was stabilized for $1 \mathrm{~h}$. At the final and cooling stage, the SPC beams were cooled gradually by the ambient air (lab conditions). The effects of the three stages on the mid span camber for all beams are summarized in Table VI. Camber versus time history for the SPC beams of Groups I, II and III are shown in Figures 8, 9 and 10 respectively. These figures elucidate that, increasing burning temperature in the first and second stages lead to steep increase in SPC camber, while a gradual camber decreasing in the third stage occurs The structure of the prestressed concrete beam exhibits upward curvature (camber) due to the eccentric prestressing force, which compressed the concrete at the lower zone (chord) of the prestressing force position and stretching the upper concrete zone (chord). The fire was positioned at the base of the furnace towards the lower face of the SPC beam, in other words, exposing a concrete beam to high temperature under sustain eccentric load led to increase in the deterioration in higher camber, despite applying external load. This denotes that the effect of temperature was more on concrete than on steel reinforcement. The structural response of beams exposure to burning can be grouped into three stages as mentioned before. In stage 1 (heating stage), concrete and strands are subject to very little degradation. The cambers in all SPC beams increase gradually and these cambers result from the generation of thermal strains caused by high thermal gradients that occur in the initial stage of fire exposure.

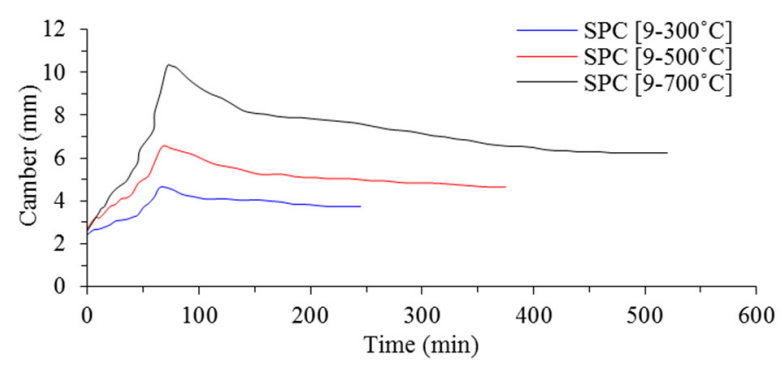

Fig. 8. Camber vs time for Group I beams at different temperatures

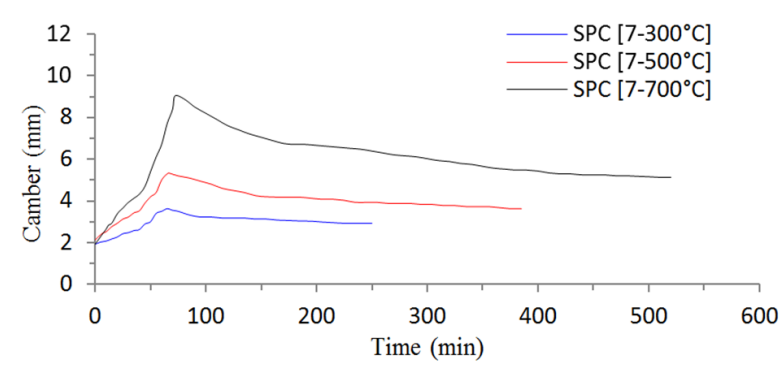

Fig. 9. Camber vs time for Group II beams at different temperatures

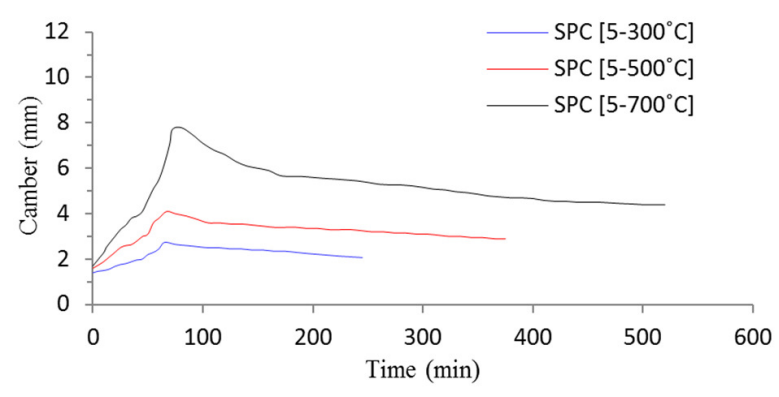

Fig. 10. Camber vs time for Group III beams at different temperatures

In the second stage, within the $1 \mathrm{~h}$ of fire exposure at the target temperature, as temperature increased in the internal layers of concrete, camber increased significantly caused by reduction in thermal concrete strength due to the formation of internal hair cracks. The interference of thermal effect into the internal layers attributed to concrete's degradation of strength and modulus of elasticity more than that of strand. Then camber increased at a higher pace. In addition, camber increment is essentially attributed to high creep strains 
subsequent from high temperatures in concrete which is composed of different materials and strands. The value of maximum camber at the end of the second stage is shown in Table VI. We can see that with increasing burning temperature, the maximum camber value of SPC beams increased. At the end of stage 2 at $500^{\circ} \mathrm{C}$ and $700^{\circ} \mathrm{C}$ the maximum camber was $165 \%$ and $335 \%$ for SPC beams of 9 segments (Group I), compared with that burned at $300^{\circ} \mathrm{C}$. Whereas, it was $181 \%$ and $388 \%$ and $181 \%$ and $409 \%$ for SPC beams of 7 segments (Group II) and beams of 5 segments (Group III) respectively. The difference in the behavior (camber) of beams at each group is shown in Figures 8-10. The camber (upward deflection) increases during the heating period and reaches its maximum at the end of stage 2. The upward movement of the SPC beam is probably explained by the reduction of concrete's resistance at the location of cracking and spalling, so the residual force in the prestressing tendons caused the segmental beams to move upwards. It can be seen that at the same burning temperatures the deterioration decreases with decreasing number of segments. Exposing SPC beams of 7 and 5 segments to $300^{\circ} \mathrm{C}$ revealed that, the decrease in maximum camber at the end of stage 2 was $80 \%$ and $64 \%$ respectively while for SPC beams with 9 segments it was $88 \%$, and $70 \%$ for Group II and $93 \%$, and $78 \%$ for Group III at $500^{\circ} \mathrm{C}$, and $700^{\circ} \mathrm{C}$ burning temperatures respectively. These comparisons exhibit that increased burning temperature increased the camber through the exposure period (burning stage), whilst increased segment number increased the maximum camber and decreased the beam stiffness.

TABLE VI. CAMBER AT THE END OF EACH STAGE OF BURNING AND COOLING PROCESS FOR ALL SPC BEAMS

\begin{tabular}{|c|c|c|c|c|c|c|c|c|c|c|c|c|}
\hline \multirow{2}{*}{\multicolumn{2}{|c|}{ Group No. }} & \multirow{3}{*}{$\begin{array}{c}\begin{array}{c}\text { Initial } \\
\text { camber } \\
(\mathrm{mm})\end{array} \\
-\end{array}$} & \multicolumn{3}{|c|}{ Heating stage } & \multicolumn{3}{|c|}{ Heat stability for $1 \mathrm{hr}$} & \multicolumn{2}{|c|}{ Cooling stage } & \multirow{3}{*}{$\begin{array}{c}\begin{array}{c}\text { Final } \\
\text { camber } \\
(\mathrm{mm})^{*}\end{array} \\
-\end{array}$} & \multirow{3}{*}{$\begin{array}{c}\text { Residual } \\
\text { camber } \\
\%\end{array}$} \\
\hline & & & \multirow{2}{*}{$\begin{array}{c}\begin{array}{c}\text { Duration } \\
\text { (min) }\end{array} \\
- \\
\end{array}$} & \multirow{2}{*}{$\begin{array}{c}\begin{array}{c}\text { Variation } \\
\text { camber } \\
(\mathbf{m m})\end{array} \\
- \\
\end{array}$} & \multirow{2}{*}{\begin{tabular}{|c|}
$\begin{array}{c}\text { Accumulative } \\
\text { camber } \\
(\mathbf{m m})\end{array}$ \\
- \\
\end{tabular}} & \multirow{2}{*}{$\begin{array}{c}\begin{array}{c}\text { Duration } \\
\text { (min) }\end{array} \\
- \\
\end{array}$} & \multirow{2}{*}{$\begin{array}{c}\begin{array}{c}\text { Variation } \\
\text { camber } \\
(\mathbf{m m})\end{array} \\
- \\
\end{array}$} & \multirow{2}{*}{$\begin{array}{c}\begin{array}{c}\text { Accumulative } \\
\text { camber } \\
(\mathbf{m m})\end{array} \\
-\end{array}$} & \multirow{2}{*}{$\begin{array}{c}\begin{array}{c}\text { Duration } \\
\text { (min) }\end{array} \\
- \\
\end{array}$} & \multirow{2}{*}{\begin{tabular}{|c|}
$\begin{array}{c}\text { Variation } \\
\text { camber } \\
(\mathbf{m m})\end{array}$ \\
- \\
\end{tabular}} & & \\
\hline \multirow{4}{*}{$\mathbf{I}$} & SPC-9-R & & & & & & & & & & & \\
\hline & SPC-9-300C ${ }^{\circ}$ & 2.44 & $0-5$ & +0.2 & 2.64 & $5-65$ & +2.0 & 4.64 & $65-245$ & -0.9 & 3.74 & 153 \\
\hline & \begin{tabular}{|l|} 
SPC-9-500C \\
\end{tabular} & 2.74 & $0-7$ & +0.5 & 3.24 & $7-67$ & +3.3 & 6.54 & $67-380$ & -1.9 & 4.64 & 169 \\
\hline & ${\mathrm{SPC}-9-700 \mathrm{C}^{\circ}}^{-}$ & 2.64 & $0-12$ & +1.0 & 3.64 & $12-72$ & +6.7 & 10.34 & $72-520$ & -4.1 & 6.24 & 236 \\
\hline \multirow{4}{*}{ II } & SPC-7-R & - & - & - & - & - & - & - & - & - & - & - \\
\hline & SPC-7-300C ${ }^{\circ}$ & 1.93 & $0-5$ & +0.1 & 2.03 & $5-65$ & +1.6 & 3.63 & $65-245$ & -0.7 & 2.93 & 152 \\
\hline & SPC-7-500C ${ }^{\circ}$ & 2.13 & $0-7$ & +0.3 & 2.43 & $7-67$ & +2.9 & 5.33 & $67-380$ & -1.6 & 3.73 & 175 \\
\hline & SPC-7-700C ${ }^{\circ}$ & 1.93 & $0-12$ & $\begin{array}{l}+0.9 \\
\end{array}$ & 2.83 & $12-72$ & +6.2 & 9.03 & $72-520$ & -3.9 & 5.13 & 266 \\
\hline \multirow{4}{*}{ III } & SPC-5-R & - & - & - & - & - & - & - & - & - & - & - \\
\hline & \begin{tabular}{|l|} 
SPC-5-300C \\
\end{tabular} & 1.4 & $0-5$ & +0.07 & 1.47 & $5-65$ & +1.27 & 2.74 & $65-245$ & -0.67 & 2.07 & 150 \\
\hline & \begin{tabular}{|l|} 
SPC-5-500C \\
\end{tabular} & 1.6 & $0-7$ & +0.2 & 1.8 & $7-67$ & +2.3 & 4.1 & $67-380$ & -1.2 & 2.9 & 182 \\
\hline & SPC-5-700C ${ }^{\circ}$ & 1.7 & $0-12$ & +0.8 & 2.5 & $12-72$ & +5.2 & 7.7 & $72-520$ & -3.4 & 4.3 & 253 \\
\hline
\end{tabular}

* Final camber equals to the sum of initial camber and final camber variation. + sign denotes increased value.

At the end of the third stage the camber had a value higher than before burning. The ratio between the final camber after burning and the initial prestressing camber before burning is called the residual camber. The values of the residual camber are shown in Table VI. In general, decreasing camber of prestressed concrete beams is a sign of increasing losses in prestressing force. Increasing camber indicates that deterioration could happen in concrete strength whilst the prestressing force is not affected. Increased temperature had a bad effect on the residual camber, denoting that more deterioration occurred. The increased percentage in the residual camber for the beams of 9 segments (Group I) was 153\%, $169 \%$, and $236 \%$ for burned beams at $300^{\circ} \mathrm{C}, 500^{\circ} \mathrm{C}$, and $700^{\circ} \mathrm{C}$ respectively compared to the initial camber before burning. For the beams of 7 (Group II) and 5 segments (Group III) it was $152 \%, 175 \%$ and $266 \%$, and $150 \%, 182 \%$ and $253 \%$ for the same burning temperatures respectively. Comparing the effect with the number of segments shows that the camber increases with increasing number of segments. Exposing SPC beams composed of 7 and 5 segments to $300^{\circ} \mathrm{C}$ decreased the final camber at the end of burning and cooling cycle by $78 \%$ and $56 \%$ respectively. For SPC beams with 9 segments it was decreased by $80 \%$, and $63 \%$ for Group II and $82 \%$ and $69 \%$ for Group III, at $500^{\circ} \mathrm{C}$ and $700^{\circ} \mathrm{C}$ respectively. Figures $11-13$ show the camber difference of beams with different number of segments for the tested burning temperatures.

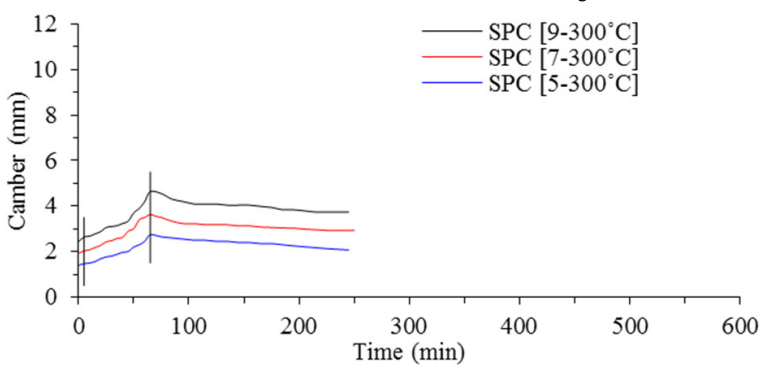

Fig. 11. Camber-time plot of SPC beams with different segment number during burning at $300^{\circ} \mathrm{C}$ and cooling cycle

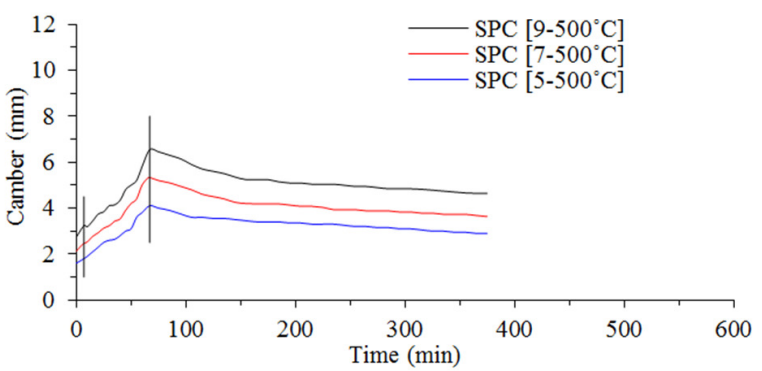

Fig. 12. Camber-time plot of SPC beams with different segment number during burning at $500^{\circ} \mathrm{C}$ and cooling cycle 


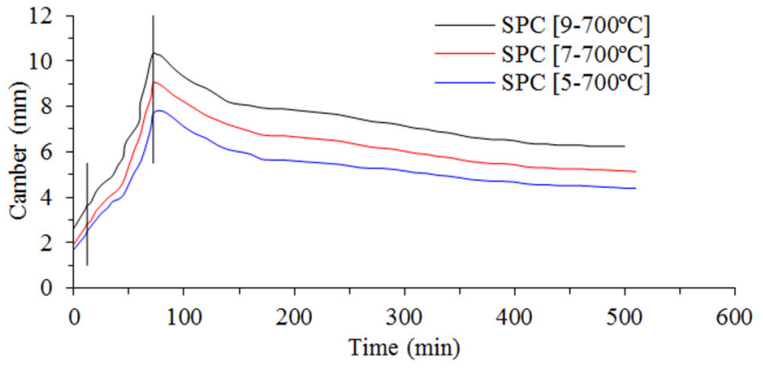

Fig. 13. Camber-time plot of SPC beams with different segment number during burning at $700^{\circ} \mathrm{C}$ and cooling cycle

\section{5) Spalling and Cracking Patterns}

During the burning test a distinct network of minor cracks occurred in SPC beams exposed to high temperature burning, however no main crack was testified. Cracking sounds were heard in some of the beams at around $15 \mathrm{~min}$ after the start of the burning test that were mainly caused by spalling. At around $100^{\circ} \mathrm{C}$, spalling started to appear, surface cracks were noticed and continued to develop until the final stage. Figures 14-16 show an appearance comparison of the beams after the exposure to fire. As mentioned before, the SPC beams were composed of different number of segments, and the burning nozzles were positioned at the lower base of the beams. These facts elucidate that due to the irregularity of fire distribution, deterioration was noticed at some segments more than others and that this difference had marginal effects on the distribution of hairline cracks on the beam surfaces. At $300^{\circ} \mathrm{C}$ the beams exhibited spalling cracks at some regions on the surface of the beam depth and at the edges near the fire source (Figure 14). Short cracks occurred in all the surfaces of the SPC beams and were concentrated in the joint positions between beam segments.

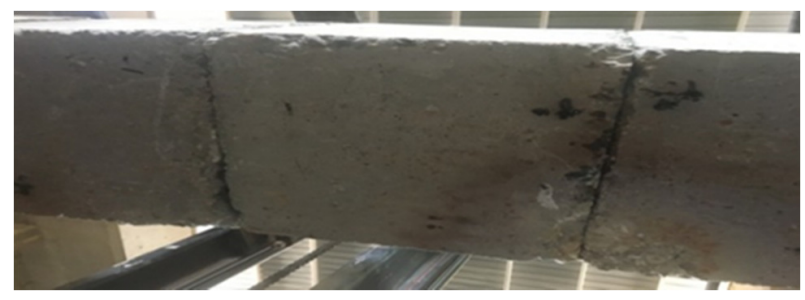

(a) Specimen spalling at $300^{\circ} \mathrm{C}$

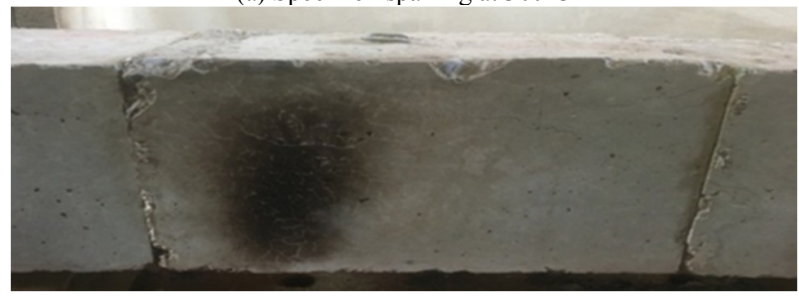

(b) Specimen hairline at $300^{\circ} \mathrm{C}$

Fig. 14. Spalling and surface hairline cracks in surface (bottom fiber) of specimens near the fire at $300^{\circ} \mathrm{C}$

At $500^{\circ} \mathrm{C}$ the SPC beams have suffered spalling at some regions in the surface and edges near to the fire source and surface hairline cracks were observed (Figure 15). It is clear that the spalling effects at the bottom surface of the beams were deeper than those of specimens at $300^{\circ} \mathrm{C}$ and the surface hairline cracks were more and longer. Hairline cracks at this temperature went deeper between segments in the joint positions and occurred in the bottom surface at prestressing steel position. Naturally, the spalling was observed in the SPC beams burned at $700^{\circ} \mathrm{C}$. The map-cracking and separation of concrete cover were more and deeper. After cooling, the spalling and the network of minor cracks in specimens increased as exhibited in Figure 16.

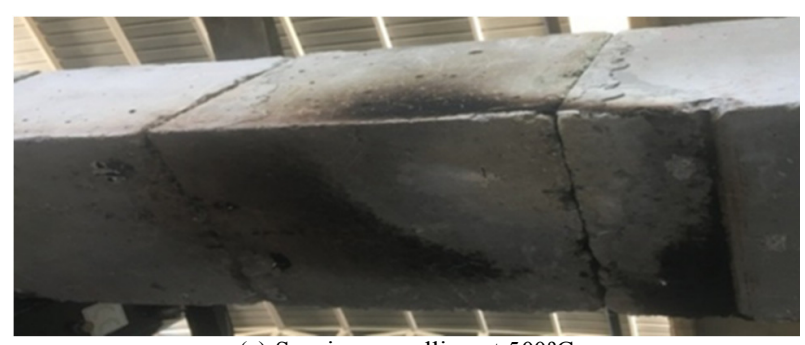

(a) Specimen spalling at $500^{\circ} \mathrm{C}$

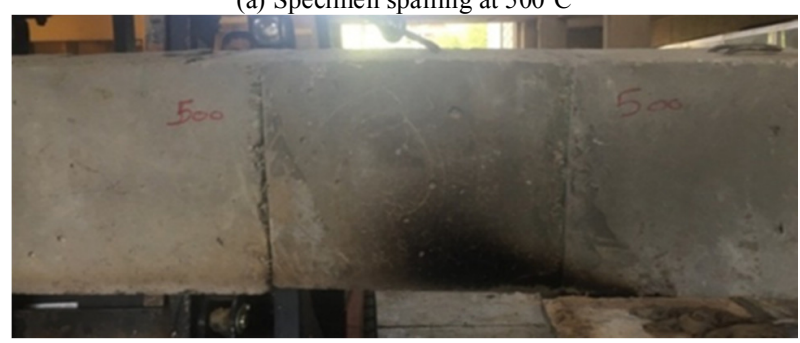

(b) Specimen hairline at $500^{\circ} \mathrm{C}$

Fig. 15. Spalling and surface hairline cracks in surface (bottom fiber) of specimens near the fire at $500^{\circ} \mathrm{C}$

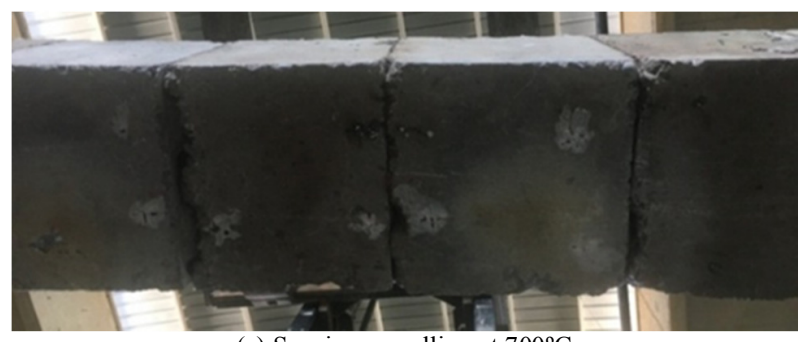

(a) Specimen spalling at $700^{\circ} \mathrm{C}$

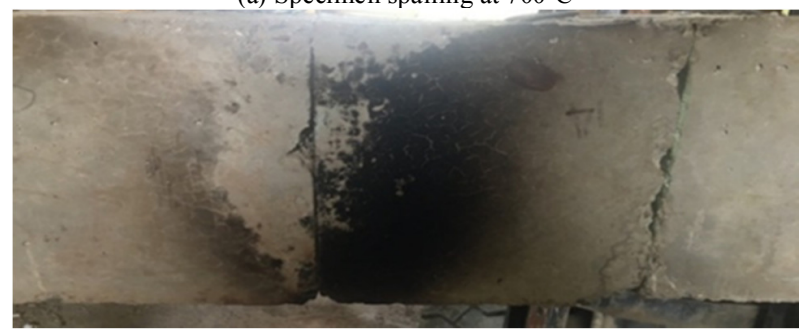

(b) Specimen hairline at $700^{\circ} \mathrm{C}$

Fig. 16. Spalling and surface hairline cracks in surface (bottom fiber) of specimens near the fire at $300^{\circ} \mathrm{C}$

Author in [17] reported that between $100^{\circ} \mathrm{C}$ and $200^{\circ} \mathrm{C}$ of a slow temperature rise, the first effects in concrete will occur due to high thermal stresses caused from fast heating and pressure caused by moisture evaporation inside the porous concrete, which the concrete structure is not able to dissipate. 
These movements cause the development of cracks and the eviction of pieces from the surface layers of the beam material. At $300^{\circ} \mathrm{C}$, concrete starts to shrink at a faster rate and surface relatively short hairline cracks begin to form. The surface moisture evaporates faster than it can be replaced by rising bleed water, leading the surface to shrink more than the inside concrete. As the internal layers of concrete inhibit the shrinkage of the surface layer, stresses grow which exceed the concrete's tensile strength, causing the surface cracks. The aggregates start to deteriorate at temperatures between $500^{\circ} \mathrm{C}$ to $700^{\circ} \mathrm{C}$ because calcium hydroxide starts to dehydrate at that temperature range. Calcium hydroxide is a hydration output of most Portland cements, the quantity being dependent at the specific cement being utilized.

\section{CONCLUSIONS}

- The camber due to prestressing force decreases with decreasing number of segments. The percentage decrease in the average camber was $79 \%$ and $62 \%$ for SPC beams of 7 and 5 segments compared with beams of 9 segments for beams having the same total length and cross section.

- The fact that the fire was positioned at the base of the furnace toward the lower face of the SPC beams, i.e. the beams were exposed to high temperature under sustain eccentric prestressing force, led to increase in deterioration and to higher camber regardless of the applied external downward load. This denotes that the effect of temperature on concrete was more than that on steel reinforcement.

- Increasing burning temperature in the first and second stages led to steep increase in the SPC camber, while a gradual camber decreasing was observed in the third stage (cooling stage).

- For identical SPC beams made up of 9 segments, the value of maximum camber at the end of target temperature period increased at burning temperature $500^{\circ} \mathrm{C}$, and $700^{\circ} \mathrm{C}$ by $165 \%$, and $335 \%$ compared with the one at $300^{\circ} \mathrm{C}$. Likewise, it was $181 \%$ and $388 \%$ and $181 \%$ and $409 \%$ for SPC beams of 7 and 5 segments for the same burning temperatures. Correspondingly, the camber at this stage compared to the initial value was $182 \%, 220 \%$, and $354 \%$ for SPC beams of 9 segments at $300^{\circ} \mathrm{C}, 500^{\circ} \mathrm{C}$, and $700^{\circ} \mathrm{C}$, respectively. Likewise, it was $183 \%, 236 \%$, and $421 \%$ and $191 \%, 244 \%$, and $406 \%$ for SPC beams of 7 and 5 segments at the same burning temperatures respectively.

- Increasing burning temperature had a bad effect on the residual final camber at the end of burning and cooling cycle, denoting more deterioration occurred. The increase percentage in the residual camber for SPC beams of 9 segments was $153 \%, 169 \%$, and $236 \%$ for burned beams at $300^{\circ} \mathrm{C}, 500^{\circ} \mathrm{C}$, and $700^{\circ} \mathrm{C}$ respectively compared to the initial camber before burning. Whilst, for SPC beams of 7 and 5 segments it was $152 \%, 175 \%$ and $266 \%$, and $150 \%$, $182 \%$ and $253 \%$ for the same temperatures.

- Comparing the effect of segment number on the residual camber of post fire SPC beams, the results show that, camber decreases with decreasing number of segments.
Exposing SPC beams composed of 7 and 5 segments to $300^{\circ} \mathrm{C}$ decreased the final camber by $78 \%$ and $56 \%$ respectively compared to that of 9 segments. It decreased by $80 \%$ and $63 \%$, and $82 \%$ and $69 \%$ for SPC beams composed of 7 and 5 segments compared to 9 segments at $500 \mathrm{C}$, and $700^{\circ} \mathrm{C}$ respectively.

\section{REFERENCES}

[1] M. Al-Gorafi, A. Ali, I. Othman, M. Jaafar, M. Anwar, "Externally Prestressed Monolithic and Segmental Concrete Beams under Torsion: a Comparative Finite Element Study", IOP Conference Series: Materials Science and Engineering, Vol. 17, 2011

[2] C. Sivaleepunth, J. Niwa, D. Nguyen, T. Hasegawa, Y. Hamada, "Shear Carrying Capacity of Segmental Prestressed Concrete Beams", Doboku Gakkai Ronbunshuu E, Vol. 65, No. 1, pp. 63-75, 2009

[3] D. Nguyen, K. Watanabe, J. Niwa, T. Hasegawa, "Modified Model for Shear Carrying Capacity of Segmental Concrete Beams with External Tendons", Doboku Gakkai Ronbunshuu E, Vol. 66, No. 1, pp. 53-67, 2010

[4] M. Algorafi, A. Ali, I. Othman, M. Jaafar, M. Anwar, "Experimental study of externally prestressed segmental beam under torsion", Engineering Structures, Vol. 32, No. 11, pp. 3528-3538, 2010

[5] Y. Chan, X. Luo, W. Sun, "Compressive strength and pore structure of high-performance concrete after exposure to high temperature up to $800^{\circ}$ C", Cement and Concrete Research, Vol. 30, No. 2, pp. 247-251, 2000

[6] C. Poon, S. Azhar, M. Anson, Y. Wong, "Comparison of the strength and durability performance of normal- and high-strength pozzolanic concretes at elevated temperatures", Cement and Concrete Research, Vol. 31, No. 9, pp. 1291-1300, 2001

[7] B. Georgali, P. Tsakiridis, "Microstructure of fire-damaged concrete. A case study", Cement and Concrete Composites, Vol. 27, No. 2, pp. 255259,2005

[8] F. Aslani, "Prestressed concrete thermal behaviour", Magazine of Concrete Research, Vol. 65, No. 3, pp. 158-171, 2013

[9] L. Zhang, Y. Wei, F. Au, "Mechanical Properties of Prestressing Steel at Elevated Temperature and After Cooling", Australasian Conference on the Mechanics of Structures and Materials, Southern Cross University, Australia, December 9-12, 2014

[10] I. Fletcher, S. Welch, J. Torero, R. Carvel, A. Usmani, "Behaviour of concrete structures in fire", Thermal Science, Vol. 11, No. 2, pp. 37-52, 2007

[11] M. Abramowicz, R. Kowalski, "Residual Mechanical Material Properties for the Reassessment of Reinforced Concrete Structures After Fire", 9th International Conference on Modern Building Materials, Structures and Techniques, Vilnius, Lithuania, May 16-18, 2007

[12] J. Outinen, P. Makelainen, "Mechanical properties of structural steel at elevated temperatures and after cooling down", Fire and Materials, Vol. 28, No. 24, pp. 237-251, 2004

[13] W. Dias, "Some properties of hardened cement paste and reinforcing bars upon cooling from elevated temperatures", Fire and Materials, Vol. 16, No. 1, pp. 29-35, 1992

[14] K. Umran, Fire Flame Exposure Effect on Some Mechanical Properties of Concrete, MSc Thesis, Babylon University, 2002

[15] M. Kadhum, "Effect of Burning by Fire Flame on the Behavior of Reinforced Concrete Beam Models", Journal of Babylon University, Vol. 21, No. 5, 2011

[16] J. J. Myers, W. L. Bailey, "Seven-Wire Low Relaxation Prestressing Tendon Subjected to Extreme Temperature: Residual Properties", International Journal of Engineering Research and Science \& Technology, Vol. 4, No. 3, pp. 223-239, 2015

[17] R. Jansson, "Fire spalling of concrete - A historical overview", MATEC Web of Conferences, Vol. 6, Article ID: 01001, 2013 